
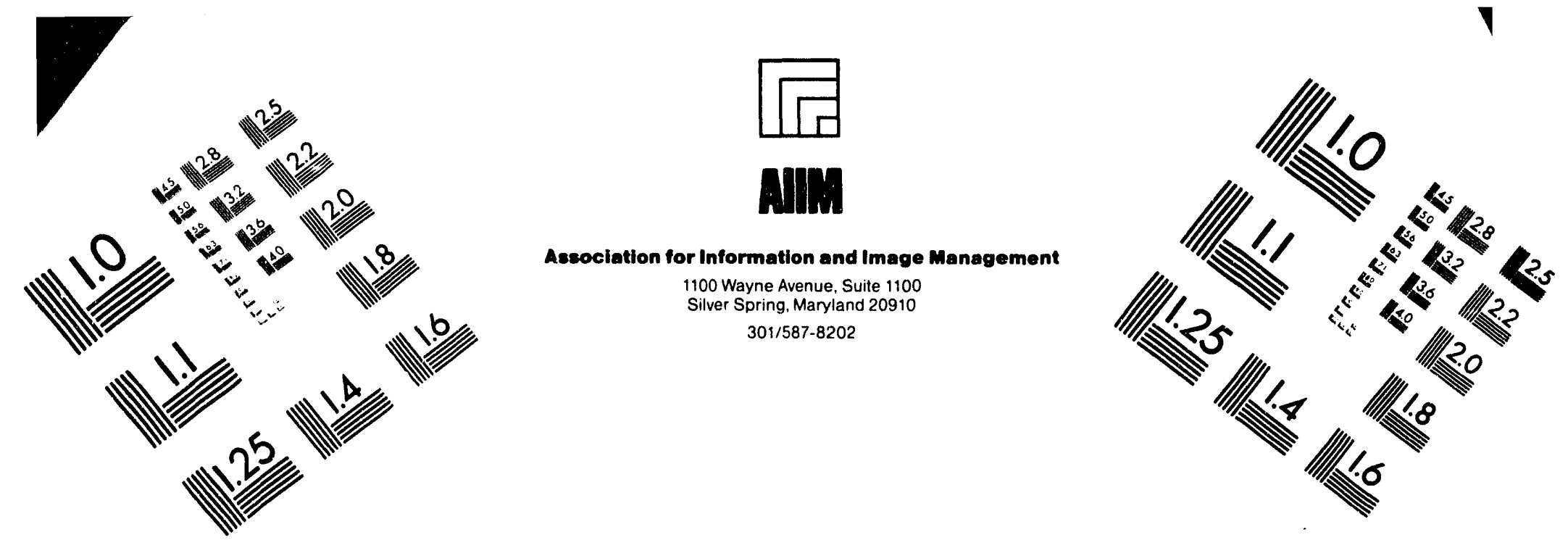

\title{
Centimeter
}

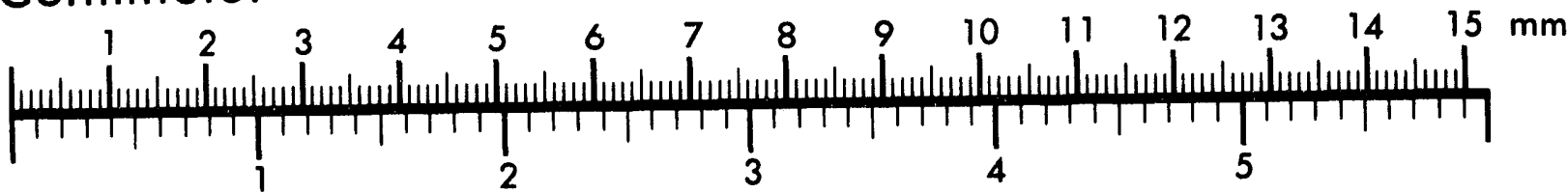
Inches
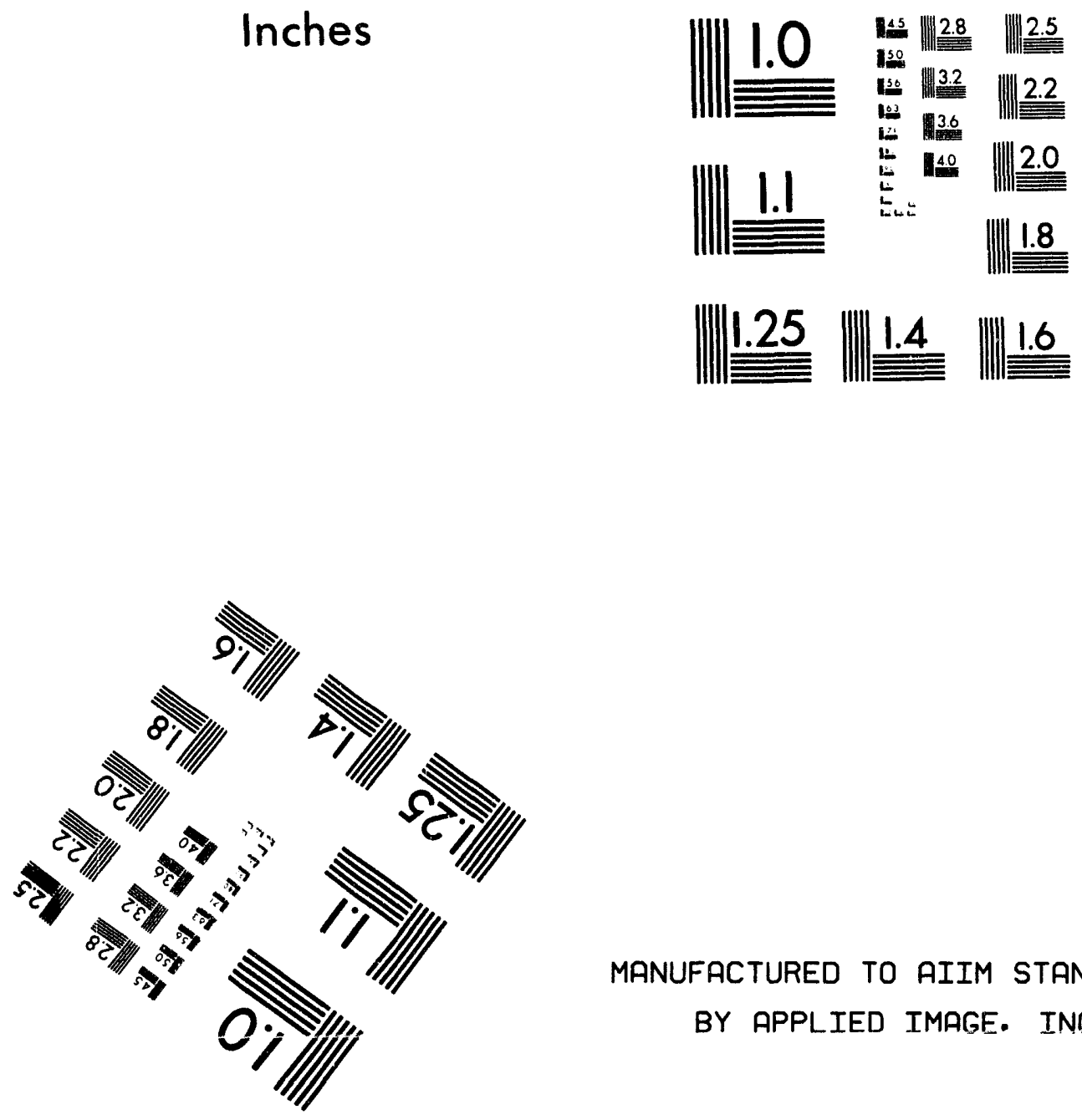

MANUFACTURED TO AIIM STANDARDS

BY APPLIED IMAGE. INC:

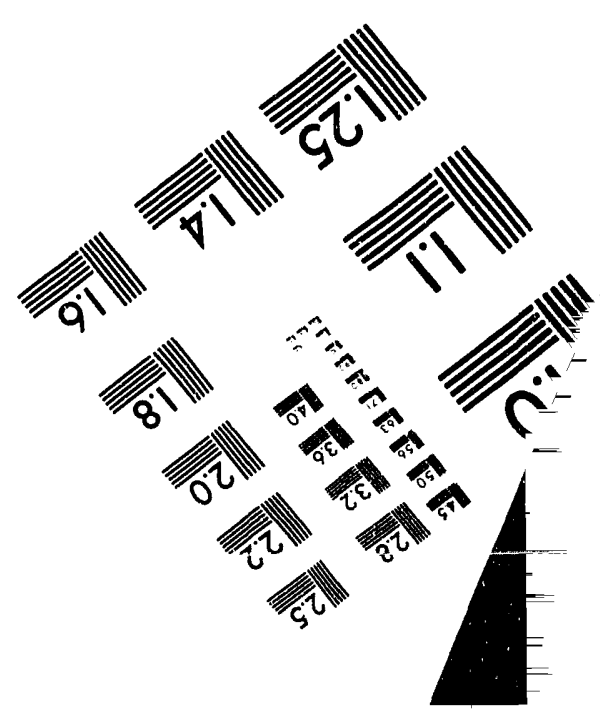



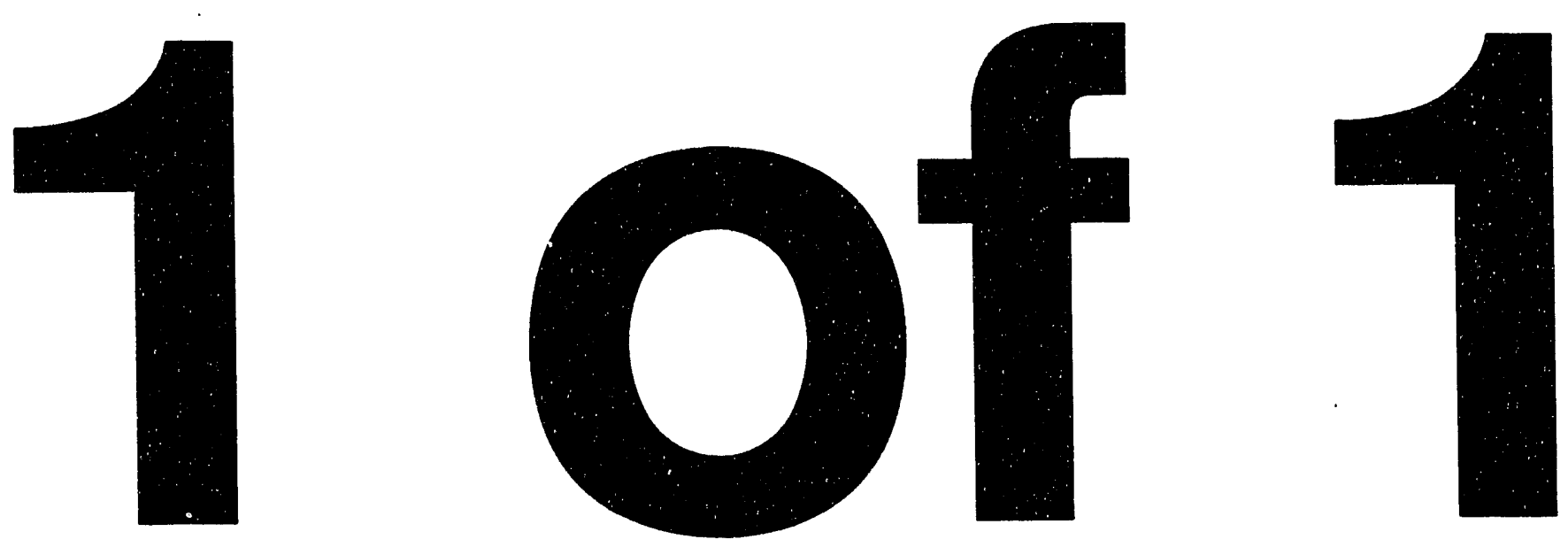
LBL-33291

UC-410

LSGN-125

\section{THE ALS STORAGE RING RF SYSTEM}

B. TAYLOR, C.C. LO, K. BAPTISTE, J. GUIGLI, and J. JULIAN

ACCELERATOR and FUSION RESEARCH DIVISION

Lawrence Berkeley Laboratory

University of California

Berkeley, CA 94720

MAY 1993 


\title{
The ALS Storage Ring RF System*
}

\author{
B. Taylor, C.C. Lo, K. Baptiste, J. Guigli, and J. Julian \\ Lawrence Berkeley Laboratory, University of California \\ 1 Cyclotron Road, Berkeley, CA 94720 USA
}

\section{Abstract}

The AlS Storage Ring RF System is characterized by the use of the following features:

1. High power loading of two single cell cavities.

2. The use of a tubular ceramic input window employing aperture coupling.

3. The use of waveguide filters and matchers designed for HOM absorption.

4. A comprehensive HOM monitoring system.

5. The use of waveguide water-wedge loads for the magic tee and circulator loads.

The results of cavity measurements and high power tests are reported together with the performance of the system during the commissioning and operation phases of the ALS project. Plans for future window development are discussed.

\section{INTRODUCTION}

The ALS Storage Ring RF system employs two single cell cavities fed via a magic " $T$ " from a circulator protected high power $500 \mathrm{MHz}$ klystron. The system is capable of delivering $150 \mathrm{~kW} \mathrm{cw}$ at each cavity input window. Some unusual features of the system are the use of tubular ceramic cavity coupling windows and the use of water wedge waveguide loads for the circulator and magic tee[1].

\section{RF CAVITIES DESIGN AND CONSTRUCTION}

The RF cavities are a further adaptation, progression and development of the aperture coupled toroidal cavities used at the "SRS" Daresbury Laboratory machine. Firstly, the cooling system of the cavity was redesigned by the manufacturer to dissipate $70 \mathrm{~kW}$ employing a turbulent flow of $\sim 130 \mathrm{gpm}$ (US) and a $\Delta t$ of $2^{\circ} \mathrm{C}$. Extra cooling was also added to the waveguide connecting flange and the tuner neck area. Secondly, the disc ceramic input window of the SRS design was replaced by a ceramic cylinder which extends the full 18" of the WR 1800 waveguide greater dimension. The cavity will, however, still accommodate disc windows. Thirdly, a hybrid SRS/LEP tuner was designed using a LEP drive system but retaining the SRS-style non-contacting tuner and tuner well arrangement. Fourthly, the manufacturer[2], who also made the SRS cavities, chose an inside out arrangement as compared to the SRS construction method. The inner shell of the ALS cavity is machined and welded whereas the complex outer shell and water passages are electroformed. The general arrangement of the bare cavity is shown in Figure 1. The higher order mode damping port is at the right of the picture.

\footnotetext{
*This work was supported by the Director, Office of Energy Research, Office of Basic Energy Sciences, Materials Sciences Division of the U.S. Department of Energy under Contract No. DEAC03-76SF00098.
}

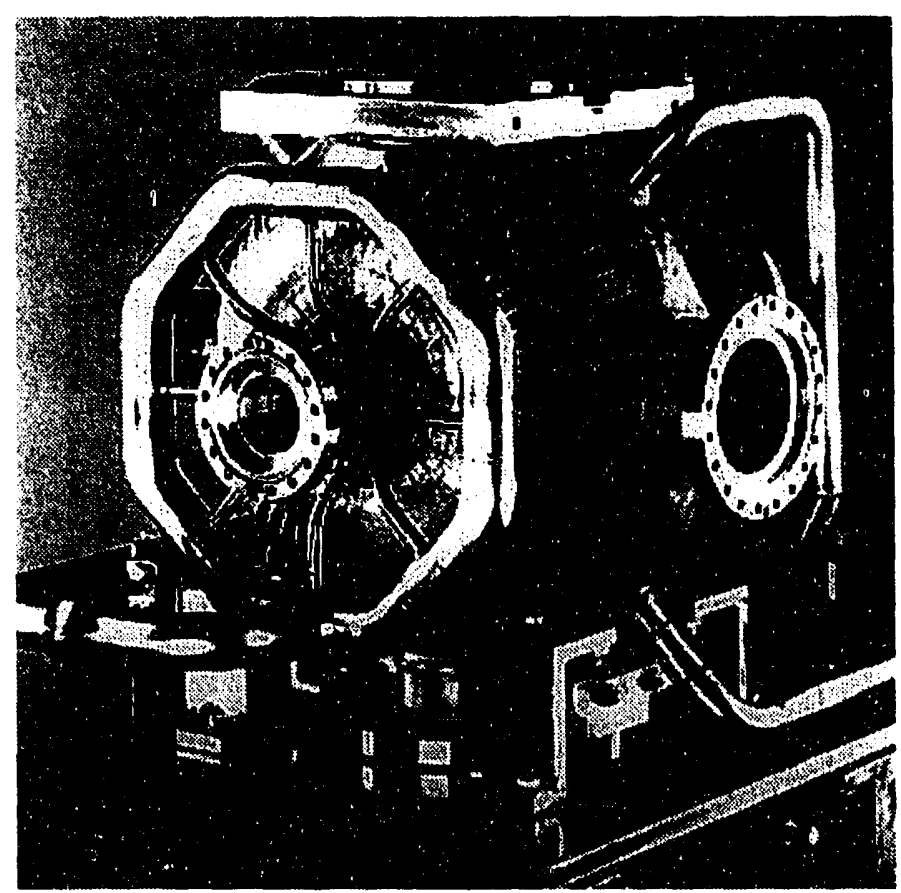

Figure 1. Single Cell Cavity [2]

\section{CAVITIES MEASUREMENT AND PERFORMANCE}

Table 1

Shows the Measured Performance of Each Cavity

\begin{tabular}{|c|c|}
\hline Unloaded Q & $=40,000$ \\
\hline Shunt Impedance & $=10 \mathrm{M} \Omega\left(2 \mathrm{ZT} \mathrm{T}^{2} \mathrm{~L}\right)$ \\
\hline $\begin{array}{l}\text { Design Peak Effective Volts } \\
\text { VPT }\end{array}$ & $=750 \mathrm{kV}$ \\
\hline Mechanical Tuner Range & $=-0.6 \mathrm{MHz}$ to $+3 \mathrm{MHz}$ \\
\hline Coupling Factor $\boldsymbol{B}$ & $\begin{array}{c}=1 \text { to } 3 \text { with tubular } \\
\text { window }\end{array}$ \\
\hline Max Power Dissipation Test & $\begin{array}{c}=70 \mathrm{~kW} \mathrm{cw} \Delta \mathrm{t} 2^{\circ} \mathrm{C} \text { inlet } \\
\text { to outlet }\end{array}$ \\
\hline $\begin{array}{l}\text { Normal Controlled Water } \\
\text { Temperature }\end{array}$ & $=40^{\circ} \mathrm{C} \pm 0.5^{\circ} \mathrm{C}$ \\
\hline $\begin{array}{l}\text { Highest Outer Envelope Spot } \\
\text { Temperature }\end{array}$ & $=50^{\circ} \mathrm{C}(70 \mathrm{~kW}$ input water \\
\hline $\begin{array}{l}\text { Ceramic Window } \\
\text { Temperature Rise }\end{array}$ & $\begin{array}{c}=0.2^{\circ} \mathrm{C} / \mathrm{kW} \text { (at mid point } \\
\text { of tube) }\end{array}$ \\
\hline
\end{tabular}

Cavities were tested under vacuum to $70 \mathrm{~kW} \mathrm{cw}$ in the LBL cavity test facility. Some instances of sparking due to dc charging of the ceramic were encountered at $\sim 50 \mathrm{~kW}$. This effec: was either traced to inadequate window antimultipactor coating, or the problem conditioned out with prolonged 
running. This exercise proved the excellence of the window arc detectors designed by C.C. Lo. A conditioning period of about 20-30 hrs was normally adequaiv ior the cavities.

At the time of writing, two cavities have operated in the ALS storage ring with a total input of $\sim 110 \mathrm{~kW}$ producing a $400 \mathrm{~mA}$ (250 Bunch) stored beam at $1.5 \mathrm{GeV}$, lifetime being vacuum limited at this stage.

\section{WAVEGUIDE SYSTEM AND HOM ABSORBERS}

The basic waveguide HOM filters and HOM monitoring devices follow the proposals made in the authors' original ALS RF paper[1] of 1989. The actual layout of the waveguide system is shown in Figure 3.

The magic tee dual $\mathrm{H}$ plane and $\mathrm{E}$ plane HOM filters and tee wedge water load are accommodated on the shield tunnel roof, feeding downwards to the cavities.

The waveguide $300 \mathrm{~kW}$ circulator and load are also on the tunnel roof. This layout has proved very compact and has released valuable real estate at ground level for experimenters' use. The waveguide wedge loads although large have worked well providing an excellent match and acting as power absorbers over a wide range of frequencies. Quiet in operation the loads share one 3/4 HP pump for water circulation

Numeric data on the power absorbed by the HOM filters and "transparent" matchers, when the cavities are beam excited, has not yet been collected. The fact, however, that a $400 \mathrm{~mA} 250$ bunch beam of $1.5 \mathrm{GeV}$ can be rapidly and smoothly accumulated is significant. Plentiful evidence of
HOM excitation is visible on all of the 30 pick up antennae available in the HOM damping systems. When running a $40 \mathrm{~mA}$ mean, 4 bunch beam, HOM power interference was experienced by ion gages and IR temperature monitors mounted on the cavity. No gross beam effects however, were noticed. An examination of the ALS cavity HOM characteristics is presented in a companion paper[3].

\section{FUTURE DEVELOPMENTS}

The presence of a ceramic disc window in the coupling port $0:$ a cavity lowers the cut off frequency of that port. As a result, for the same size coupling port, a higher coupling factor $B$ may be obtained with a disc window than with a tubular window. The relative figures for an ALS cavity are, Bmax disc 5.0, Bmax tubular 3.0. Experiments have been conducted showing that the coupling factor of a tubular window may be increased by providing ridges on the coupling aperture in the manner of a ridged waveguide. Such a shaped aperture may also be effective in increasing the coupling out of lower frequency HOM components, both from the input coupling port and other ports.

A problem sometimes encountered with ceramic windows of all kinds is the phenomenon of dc charging of the ceramic, the attendant dc sparking leading to RF arcing. The ALS tubular window has been designed with a central access/inspection port in the top cap. The effect of a biased collector electrode coaxial with the window ceramic will be explored in order to diagnose or possibly suppress the charging action.

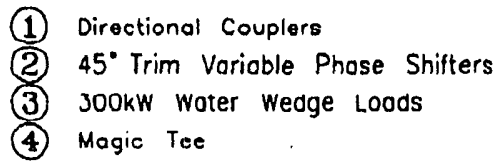

(1) Directional Couplers
(2) $45^{\circ}$ Trim Voriable Phose Shifters
(3) $300 \mathrm{~kW}$ Woter Weoge Loods
(4) Magic Tee
(5) $1.5 \mathrm{~kW}$ Bifurcated Air Cooled HOM Loods

(6) Sliding Bifurcated Shorts

(7) $300 / 300 \mathrm{kw}$ Ciculator

(B) $500 \mathrm{MHz}$ Covity

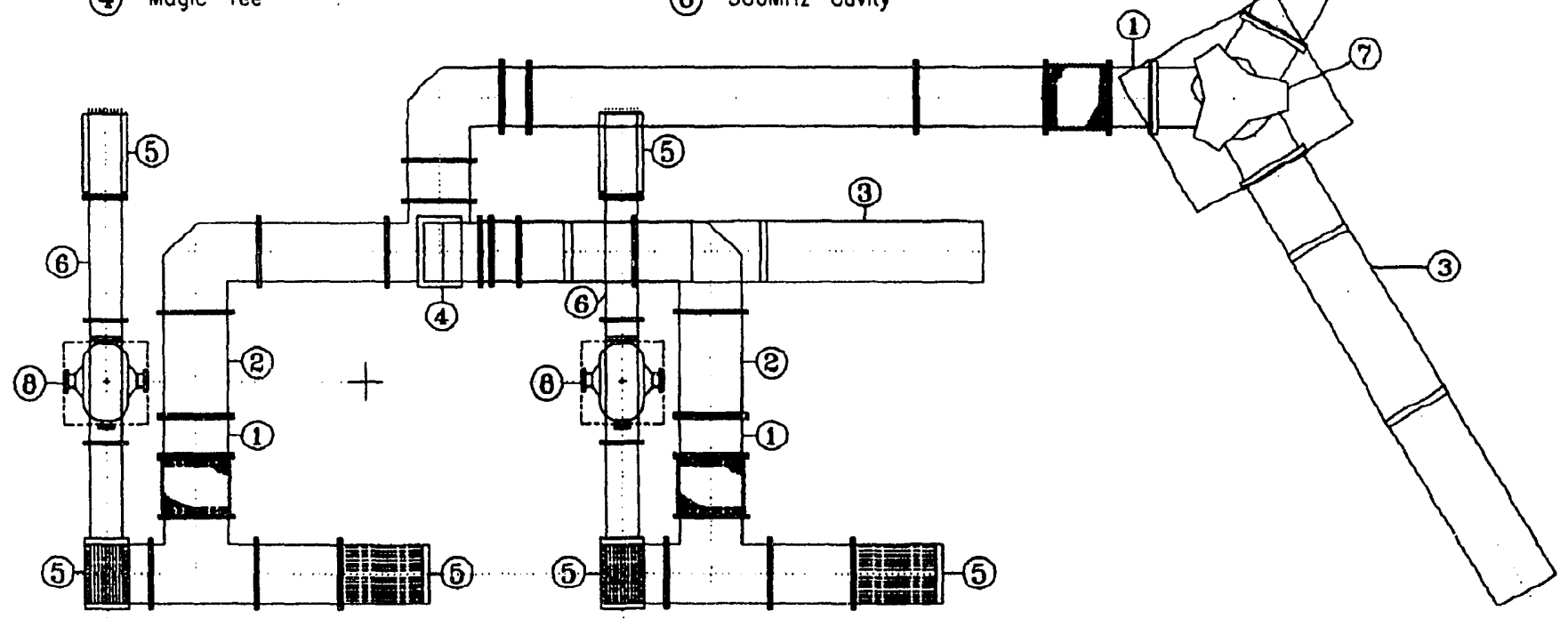

XPQ O34-BEO

Figure 2. Storage Ring Roof Waveguide Layout 


\section{ACKNOWLEDGMENTS}

Thanks are due to many people and organizations who provided advice and encouragement during the design and construct of this project. The authors would, however, in particular like to thank the scientific and engineering staff of the SRS Daresbury Laboratory who provided both technical and material assistance.

\section{REFERENCES}

[1] B. Taylor, K. Baptiste, H. Lancaster, and C.C. Lo, Advanced Light Source Storage Ring RF System, Proceedings of 1989 IEEE PAC, Vol. 1, pp. 124-125, LBL-25978.

[2] Normal Conducting RF Cavities for Accelerators Pamphlet, Accelerator and Magnet Technology Interatom/Siemens.

[3] Measurements of the Higher Order Modes of the ALS 500 MHZ Accelerating Cavities, J. Corlett, J. Byrd, LBL, IEEE PAC93. 

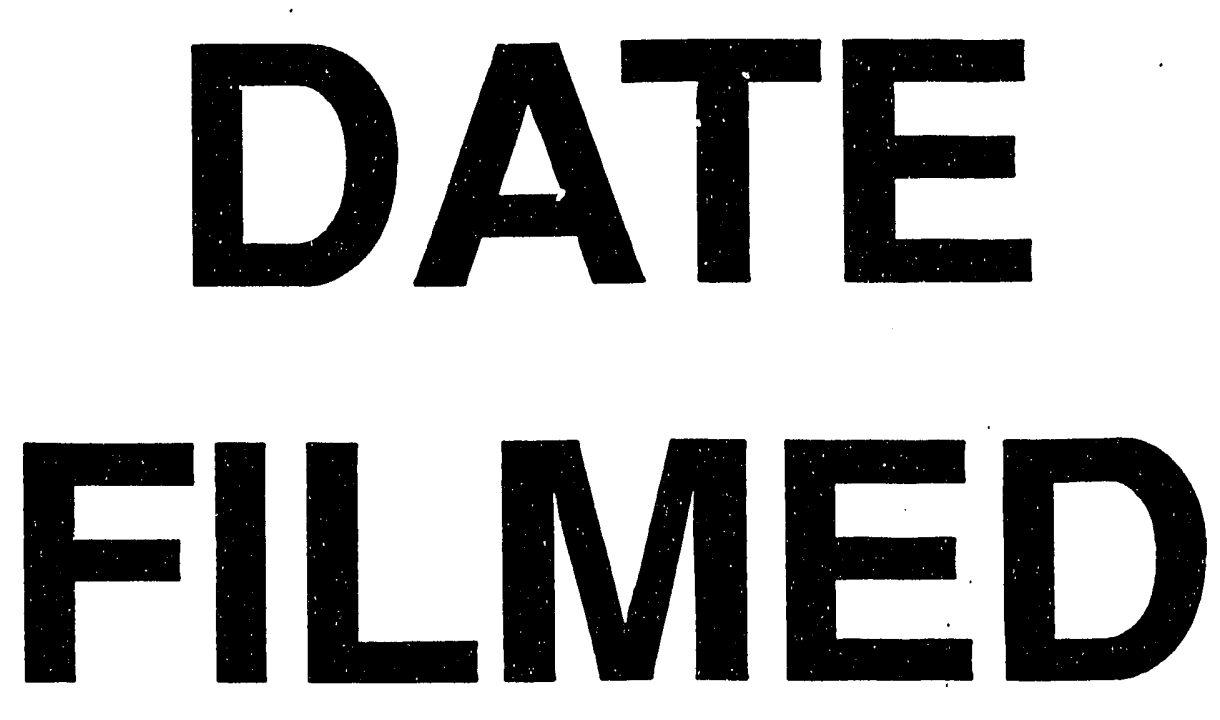

$9 / 28 / 93$
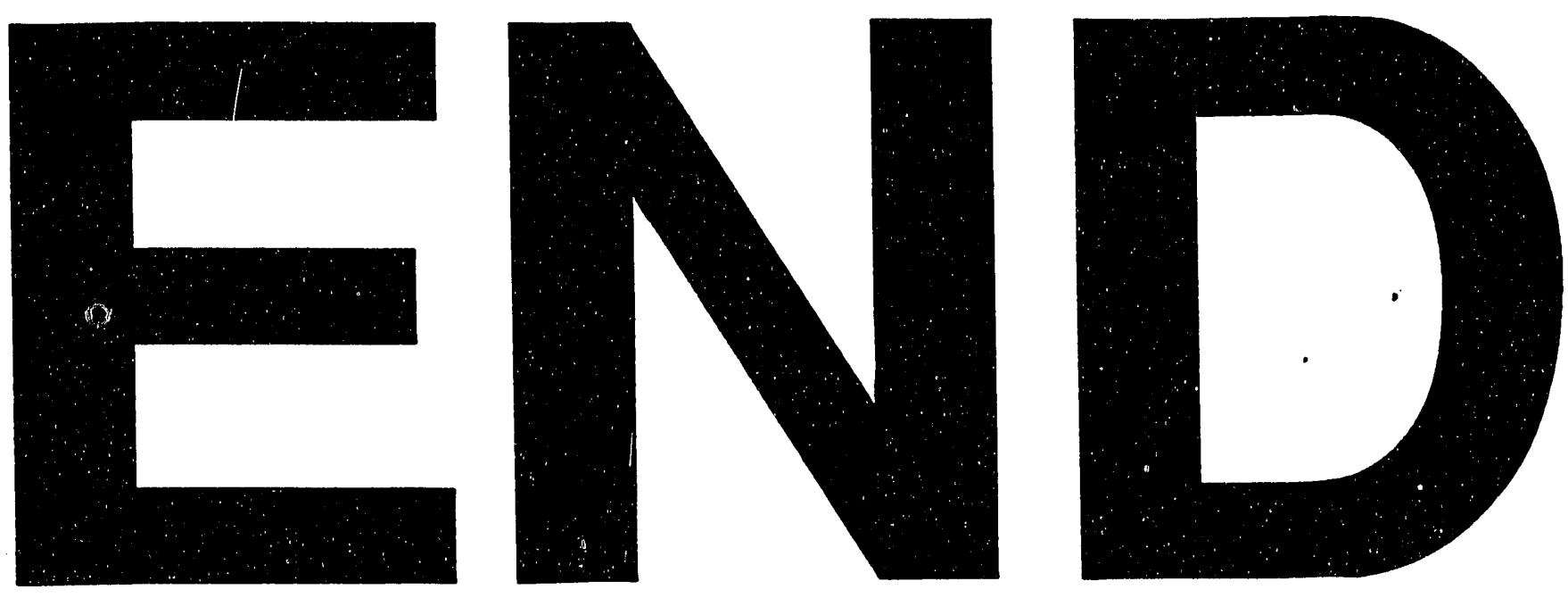
